\title{
Article \\ Insufficient Vitamin C Levels among Adults in the United States: Results from the NHANES Surveys, 2003-2006
}

\author{
Jennifer Crook ${ }^{1, * \mathbb{D}}$, Ann Horgas ${ }^{2}$, Saun-Joo Yoon ${ }^{2} \mathbb{D}$, Oliver Grundmann ${ }^{3} \mathbb{D}$ and Versie Johnson-Mallard ${ }^{4}$ \\ 1 Center for Health Equity and Community Engagement Research, Mayo Clinic Hospital, \\ Jacksonville, FL 32224, USA \\ 2 Biobehavioral Nursing Science, College of Nursing, University of Florida, Gainesville, FL 32610, USA; \\ ahorgas@ufl.edu (A.H.); yoon@ufl.edu (S.-J.Y.) \\ 3 Entrepreneurial Programs in Medicinal Chemistry, College of Pharmacy, University of Florida, \\ Gainesville, FL 32610, USA; grundman@ufl.edu \\ 4 Dean, College of Nursing, Kent State University, Kent, OH 44240, USA; VJOHNS29@kent.edu \\ * Correspondence: crook.jennifer@mayo.edu
}

check for

updates

Citation: Crook, J.; Horgas, A.;

Yoon, S.-J.; Grundmann, O.;

Johnson-Mallard, V. Insufficient

Vitamin C Levels among Adults in

the United States: Results from the

NHANES Surveys, 2003-2006.

Nutrients 2021, 13, 3910.

https://doi.org/10.3390/

nu13113910

Academic Editor: Emily Sonestedt

Received: 11 October 2021

Accepted: 29 October 2021

Published: 30 October 2021

Publisher's Note: MDPI stays neutral with regard to jurisdictional claims in published maps and institutional affiliations.

Copyright: (C) 2021 by the authors. Licensee MDPI, Basel, Switzerland. This article is an open access article distributed under the terms and conditions of the Creative Commons Attribution (CC BY) license (https:/ / creativecommons.org/licenses/by/ $4.0 /)$.

\begin{abstract}
Vitamin C, well-established in immune function and a key factor in epigenetic inflammatory modifications, is only obtained through consistent dietary intake. Identifying individuals at risk for Vitamin C insufficiency may guide prevention and treatment, however, national surveillance has not been evaluated in the United States since 2006. A descriptive, cross-sectional secondary analysis was performed utilizing data from the 2003-2006 National Health and Nutrition Examination Surveys (NHANES) assessing non-institutionalized adults. Five categories of plasma Vitamin C were delineated: deficiency $(<11 \mu \mathrm{mol} / \mathrm{L})$, hypovitaminosis $(11-23 \mu \mathrm{mol} / \mathrm{L})$, inadequate $(23-49 \mu \mathrm{mol} / \mathrm{L})$, adequate $(50-69 \mu \mathrm{mol} / \mathrm{L})$, and saturating $(\geq 70 \mu \mathrm{mol} / \mathrm{L})$. Results indicated $41.8 \%$ of the population possessed insufficient levels (deficiency, hypovitaminosis, and inadequate) of Vitamin C. Males, adults aged 20-59, Black and Mexican Americans, smokers, individuals with increased BMI, middle and high poverty to income ratio and food insecurity were significantly associated with insufficient Vitamin C plasma levels. Plasma Vitamin C levels reveal a large proportion of the population still at risk for inflammatory driven disease with little to no symptoms of Vitamin $C$ hypovitaminosis. Recognition and regulation of the health impact of Vitamin C support the goal of Nutrition and Healthy Eating as part of the Healthy People 2030.
\end{abstract}

Keywords: ascorbate; Vitamin C insufficiency; public health; food insecurity; nutrition

\section{Introduction}

Prior to the Coronavirus-19 (COVID-19) pandemic, the United States (USA) led the world in the incidence of food insecurity among high-income nations [1,2], with as many as $40 \%$ of households affected [3]. Although it is not clear yet how recent restrictions such as school closures and quarantines have affected geographic locations of food insecurity, and despite research identifying insufficiencies of Vitamin $C$ to be a global issue with many countries affected [4-7], nutritional surveillance is not often part of routine screenings during clinic visits or admittance to inpatient settings. Vitamin $C$ is emerging as a potential benefit in the prevention and treatment of COVID-19 infections [8-10] and other inflammatory conditions [11-16]; though the underlying plasma Vitamin C status of individuals in the USA is currently not well-known. There exists an emergent need to identify subclinical vitamin $C$ insufficiencies $(<23 \mu \mathrm{mol} / \mathrm{L})$ because higher supplementation may be needed in patients with Vitamin $C$ hypovitaminosis to achieve the saturated levels necessary for alleviating inflammation states and supporting immune system defenses [11].

Vitamin C is a water-soluble vitamin that cannot be synthesized in the human body and is usually included in a well-balanced diet from fruits and vegetables such as strawberries, kiwis, peppers, broccoli, cauliflower, kale, pineapples, and citrus fruits, among 
others. Plasma concentration of Vitamin C is tightly regulated through intestinal absorption, tissue transport, and renal reabsorption [17] and is the second most reliable gauge of circulating Vitamin C after leukocytic measurement. Vitamin C is a well-known antioxidant possessing multiple beneficial properties. Although a comprehensive list of its full benefits has still not been clearly identified, many of its valuable properties are believed to be the result of its ability to act as an electron donor [18-20]. These include neutralizing free radical oxygen species, inhibition of low-density lipoprotein (LDL) oxidation [21], alleviating chronic inflammation [12], supporting growth and development of healthy gut microbiota [9], enhancing neutrophil motility [10,11], aiding the proliferation of natural killer cells [12], recycling Vitamin E [22,23], and enhancing the bioavailability of iron [24]. The benefits of Vitamin C in specific epigenetic inflammatory pathways, including the ability to act as a cofactor to both start and complete DNA and histone demethylations, is being realized [25-28]. Some countries are identifying the need to adjust recommend intakes based on optimal health instead of the previously defined deficiency prevention. Current recommendations for daily intake of Vitamin $C$ are inconsistent worldwide with ranges from 40 to $220 \mathrm{mg} /$ day [29] and there remains little to no consistent evaluation of population intake or standard guidelines for increased consumption/supplementation when necessary.

Nationwide monitoring of plasma Vitamin C status has not been recorded in the USA since 2006, in which $13 \%$ of the population was found to be deficient $(<10.99 \mu \mathrm{mol} / \mathrm{L})$ [30]. However, Vitamin C insufficiencies (including not only deficiency but hypovitaminosis and inadequate plasma levels) may partly explain the increased incidence of chronic inflammation common to numerous chronic diseases as well as highlight potential hindrances in immune system defense. There are multiple known Vitamin C-lowering components including stress [31,32], poverty [4,33], obesity [34,35], and smoking [36-38]. Coupled with Western low nutritionally dense, the need for plasma Vitamin C assessment in routine screenings as well as admission to inpatient settings becomes more apparent. There is much evidence supporting increased inflammation and disease with Vitamin C deficiency and hypovitaminosis, but research is identifying greater immune benefit at saturating levels [14,39], higher than currently defined adequate levels of vitamin C $(50-69 \mu \mathrm{mol} / \mathrm{L})$. There is also little to no current assessment of the range between hypovitaminosis and adequate (labeled inadequate in this study) or how this range, with no signs or symptoms of Vitamin C deficiency, relates to increased risk of inflammation and disease. The examination of the prevalence of all five categories of Vitamin C: deficiency, hypovitaminosis, inadequate, adequate, and saturating levels may benefit clinicians in prevention and treatment, rationale for supplementation during increased need, and guidance of public health policy for funding for federal dietary programs such as Food Stamps, National School Lunch Program, and Women, Infant, and Children (WIC). This study meets the goal of Nutrition and Healthy Eating as part of the Healthy People 2030 [40] to describe the prevalence of plasma levels of Vitamin C in the population of the USA based on five defined categories: deficiency $(<11 \mu \mathrm{mol} / \mathrm{L})$, hypovitaminosis $(11-23 \mu \mathrm{mol} / \mathrm{L})$, inadequate (23-49 $\mu \mathrm{mol} / \mathrm{L})$, adequate (50-69 $\mu \mathrm{mol} / \mathrm{L})$, and saturating $(\geq 70 \mu \mathrm{mol} / \mathrm{L})$.

\section{Materials and Methods}

This study is a secondary data analysis of the National Health and Nutrition Examination Survey (NHANES; 2003-2006) sponsored by the National Center for Health Statistics (NCHS), the Centers for Disease Control and Prevention (CDC). NHANES employed a multi-step randomization approach for nationally representative sampling of a non-institutionalized population, requiring sample weights to be calculated and used in analysis. Certain populations are over-sampled and sample weights are calculated so that demographics closely align with current national census information. Interviews were conducted in homes and physical examinations with laboratory tests were done in mobile examination clinic (MEC) visits. A four-year sample weight was calculated from the specific coding instructions listed on the CDC website regarding combining the 2003-2006 
surveys [30]. All participants provided informed consent and all identifying information removed prior to survey datasets being made publicly available online.

Inclusion criteria consisted of both sexes and all ethnicities, ages $\geq 20$ years of age, of non-institutionalized civilian participants, who were able to give informed consent, and participated in both questionnaire and laboratory measurements and retained complete information in all study variables. Excluded from analysis were children and participants with missing data in combined participant laboratory and questionnaire. Selection of sample participants for inclusion is identified in Figure 1. From the NHANES completed and published for the years 2003-2004 and 2005-2006, there were a total of 20,470 participants who participated. After application of the inclusion and exclusion criteria, a total of 7607 participants were included in the final sample. The study was approved by the University of Florida Institutional Review Board (IRB\# 201902929).

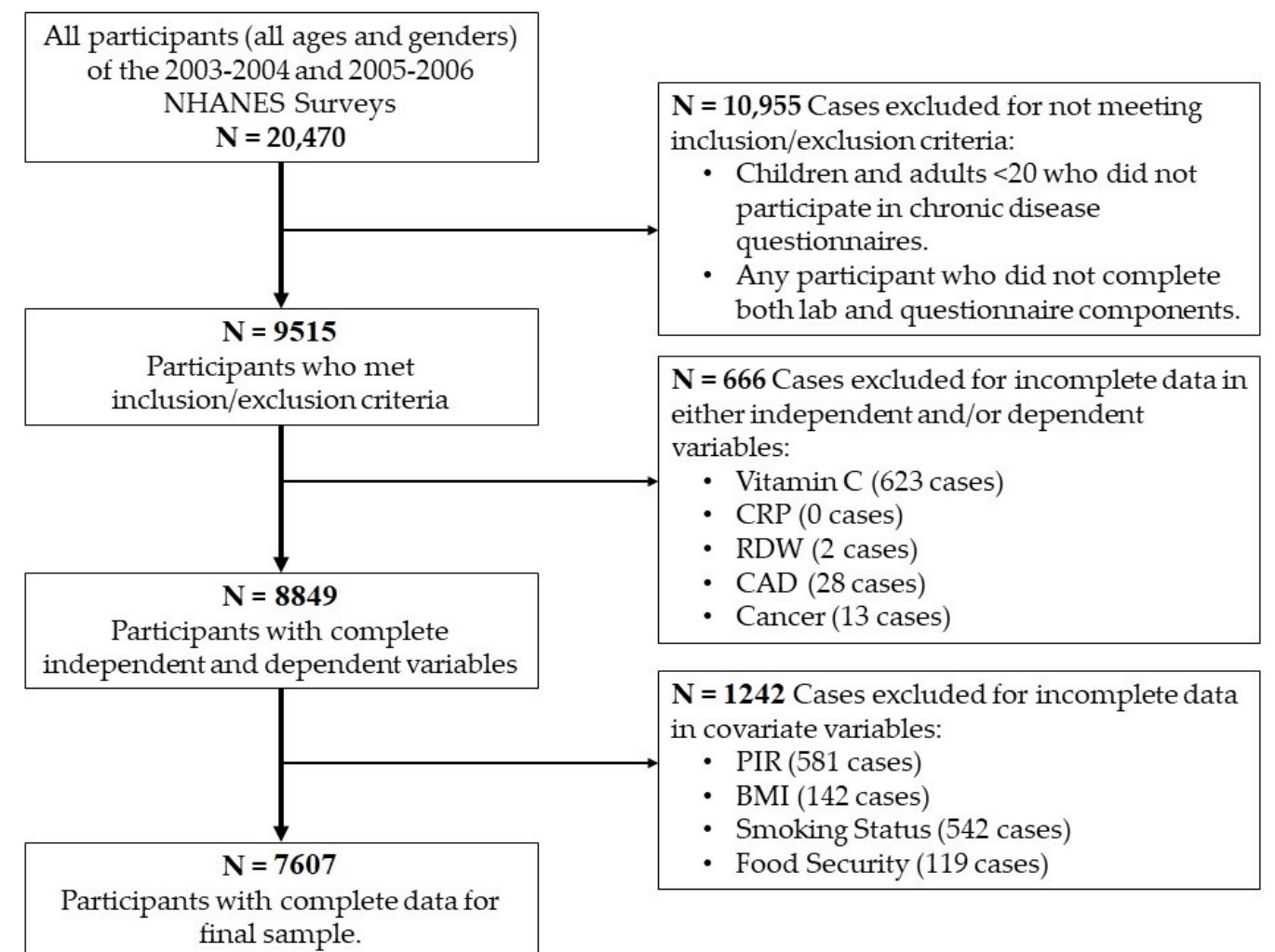

Figure 1. Sample Selection Flowsheet.

The measures, including variable names and recoding justifications are included as follows:

Sex: Sex information listed in the Demographic Data Set where respondents answered "male" or "female."

Age: Age information was also included in the Demographic Questionnaire. Respondents answered in a range of values, and individuals aged $>85$ years were top-coded at 85. As the NHANES had grouped portions of the participants by top-coding removing the ability to define this variable differently, this study recoded the age variable into three categorical variables included in analysis: Young Adult, Middle Adult, and Late Adult.

Body Mass Index (BMI): BMI measurements were listed in Exam Data. Upon initial analysis of examining outliers, one participant was excluded for an abnormally high BMI. Further examination of the respondent's listed height and weight revealed that the BMI listed was an input error and was correctly calculated, and participant included for analysis. 
Food Security: Food security information was included in the Food Security Questionnaire. Respondents answered "yes" or "no" to the question, "Are you worried you will run out of food?"

Smoking Status: Smoking status was included in the Smoking Recent Tobacco Use Questionnaire. Respondents answered "yes" or "no" to the question, "Used tobacco/nicotine in the last 5 days?"

Vitamin C: Vitamin C (ascorbic acid) in serum was measured by isocratic highperformance liquid chromatography with electrochemical detection at $650 \mathrm{mV} 1$. Peak area quantitation was based on a standard curve generated from three different concentrations of an external standard. The measured vitamin $C$ was converted from $\mathrm{mg} / \mathrm{dL}$ to $\mu \mathrm{mol} / \mathrm{L}$ by multiplying by 56.78 . NHANES maintains quality assurance and quality control protocols that meet 1988 Clinical Laboratory Improvement Act mandates. A full description of the specimen collection, laboratory processing method, and quality control procedures can be found on the NHANES website. Initial analysis identified correlations between the continuous Vitamin $C$ variable to the other tested variables. To analyze the prevalence across five ordinal strata of plasma Vitamin C categories, the Vitamin $C$ variable was recoded and grouped according to the following categories: deficiency $(0-10.99 \mu \mathrm{mol} / \mathrm{L})$, hypovitaminosis $(11-23.99 \mu \mathrm{mol} / \mathrm{L})$, inadequate $(24-49.99 \mu \mathrm{mol} / \mathrm{L})$, adequate $(50-69.99 \mu \mathrm{mol} / \mathrm{L})$, and saturating $(\geq 70 \mu \mathrm{mol} / \mathrm{L})$ based on participant plasma levels.

Ethnicity: Ethnicity information was collected in the Demographic Questionnaire. Respondents chose from the following categories: Mexican American, Other Hispanic, Non-Hispanic White, Non-Hispanic Black, or Other.

Poverty to Income Ratio (PIR): Poverty to Income Ratio information was collected in the Demographic Questionnaire. NHANES calculated PIR using Department of Health and Human Services poverty guidelines to determine qualification for financial assistance for federal aid programs such as Food Stamps, the National School Lunch Program [23]. The variable was recoded into categorical values of: High PIR (participants below $30 \%$ of the poverty line eligible for government assistance, or $\leq \$ 25,000$ per year), Medium PIR (considered middle class with a household income of $\$ 25-\$ 75,000$ per year), and Low PIR (considered high-income earners with household incomes of $>\$ 75,000$ per year).

Vitamin C Intake: Total nutrient intakes were captured in the Dietary Data Questionnaire dataset utilizing the What We Eat In America Questionnaire developed by the USA Department of Agriculture and USA Department of Health and Human Services. Participants recalled all foods and beverages eaten for two nonconsecutive days (the first interview done in the mobile exam clinic and the second conducted over the phone 3-10 days later). To identify the specific nutrients included in the intake data, the USDA Food and Nutrient Database for Dietary Studies, 2.0 (FNDDS 2.0) was utilized. Vitamin C intake was recorded as a range of values in milligrams. A full description of the quality control measures employed in obtaining dietary data may be found on the NHANES website.

Descriptive statistics were used to analyze the prevalence of plasma Vitamin C in the population of the USA Data from the 2003-2006 NHANES datasets downloaded in statistical analysis system (SAS) transport file format and Statistical Analysis System (SAS) version 9.4 (SAS Institute Inc., Cary, NC, USA). SAS files were converted to Statistical Package for the Social Sciences (SPSS) (IBM SPSS Statistics for Windows, Version 26.0. Armonk, NY, USA) for analysis. Four-year sample weights were calculated per the National Center for Health Statistics (NCHS) recommendations. A separate NHANES weighting variable was provided for researchers to analyze dietary data results as participants were more likely to have study visits that occurred on the weekend and food intake is different on weekdays versus weekends. Since two days' worth of dietary intake was evaluated in this study, the appropriate sample weights were utilized as instructed on the NHANES website. Pearson's chi-square tests were utilized for categorical variables and analysis of variance (ANOVA) testing was employed for continuous variables. The continuous variables of BMI, plasma Vitamin C, and Vitamin C intake were assessed for normality and found to be positively skewed, although with large sample sizes, violations of normality do 
not noticeably affect results and thus do not require transformations [41]. BMI and Vitamin $C$ intakes were assessed for homogeneity of variances and found the assumption violated; thus, a Welch correction was applied. In all statistical tests, a $p$-value of less than 0.05 was considered statistically significant. Means with Standard Deviations (S.D.s), percentages, and frequencies were used to present continuous variables, and proportions were used for categorical variables.

\section{Results}

A total of 7607 unique cases were utilized in this study. A description of the weighted sample characteristics is shown in Table 1 . The sample was comprised of $40.1 \%$ adults between $40-59$ years of age, $51.3 \%$ females, and $73.6 \%$ Non-Hispanic Whites. Most participants were non-smokers $(70.6 \%)$ and did not worry about running out of food $(85.9 \%)$. A significant percentage $(63.8 \%)$ of the sample was categorized as possessing high PIR levels. Mean BMI was $28.68 \mathrm{~kg} / \mathrm{m}^{2}$ (SD 6.44) and mean plasma Vitamin C level $54.63 \mu \mathrm{mol} / \mathrm{L}$ (SD 28.62).

Table 1. Vitamin C Prevalence Sample Description ( $N=7607)$.

\begin{tabular}{|c|c|c|c|c|}
\hline Characteristics & $n$ & Weighted $n(\%)$ & Mean (S.D.) & Range \\
\hline \multicolumn{5}{|l|}{ Gender } \\
\hline Male & 3699 & $48.7 \% \pm 0.7 \%$ & & \\
\hline Female & 3908 & $51.3 \% \pm 0.7 \%$ & & \\
\hline \multicolumn{5}{|l|}{ Age } \\
\hline Young Adult 20-39 & 2751 & $37.5 \% \pm 0.7 \%$ & & \\
\hline Middle Adult 40-59 & 2295 & $40.1 \% \pm 0.7 \%$ & & \\
\hline Late Adult $\geq 60$ & 2561 & $22.4 \% \pm 0.5 \%$ & & \\
\hline \multicolumn{5}{|l|}{ Race/Ethnicity } \\
\hline Mexican American & 1516 & $7.6 \% \pm 0.2 \%$ & & \\
\hline Other Hispanic & 230 & $3.4 \% \pm 0.3 \%$ & & \\
\hline Non-Hispanic White & 4035 & $73.6 \% \pm 0.5 \%$ & & \\
\hline Non-Hispanic Black & 1536 & $10.5 \% \pm 0.3 \%$ & & \\
\hline Other & 290 & $4.9 \% \pm 0.3 \%$ & & \\
\hline \multicolumn{5}{|l|}{ Family PIR ${ }^{1}$} \\
\hline High (0-1.5) & 5206 & $63.9 \% \pm 0.5 \%$ & & \\
\hline Medium (1.51-4.5) & 1614 & $22.6 \% \pm 0.5 \%$ & & \\
\hline Low $(>4.51)$ & 787 & $13.5 \% \pm 0.5 \%$ & & \\
\hline \multicolumn{5}{|l|}{ Smoking Status } \\
\hline Yes & 1997 & $29.4 \% \pm 0.6 \%$ & & \\
\hline No & 5610 & $70.6 \% \pm 0.6 \%$ & & \\
\hline \multicolumn{5}{|l|}{ Food Insecure } \\
\hline Yes & 1449 & $14.1 \% \pm 0.4 \%$ & & \\
\hline No & 6158 & $85.9 \% \pm 0.4 \%$ & & \\
\hline $\mathrm{BMI}^{2}$ & 7607 & & $28.68(6.44)$ & $13.36-76.07$ \\
\hline Plasma Vitamin $C^{3}$ & 7607 & & $54.37(28.62)$ & $0.6-274.20$ \\
\hline Vitamin C Intake Day $1^{4}$ & 7468 & & $91.91(104.14)$ & $0.0-2261.00$ \\
\hline Vitamin C Intake Day $2^{4}$ & 6886 & & $95.30(99.31)$ & $0.0-1308.40$ \\
\hline
\end{tabular}

${ }^{1}$ Poverty to Income Ratio; ${ }^{2}$ Body Mass Index $\left(\mathrm{kg} / \mathrm{m}^{2}\right) ;{ }^{3}$ Plasma Vitamin C $(\mu \mathrm{mol} / \mathrm{L}) ;{ }^{4}$ Vitamin C Intake $(\mathrm{mg})$.

\subsection{Prevalence of Vitamin C Levels}

The prevalence of plasma Vitamin C levels in the population of the USA is delineated by five quartiles: deficiency, hypovitaminosis, inadequate, adequate, and saturating (see Figure 2). More than half of the participants (58.2\%) had sufficient levels of plasma Vitamin C, composed of $32.4 \%$ with adequate and $25.8 \%$ with saturating plasma Vitamin C levels. However, $41.8 \%$ of the sample had insufficient levels of Vitamin C. Specifically, $6.1 \%$ of the 
participants exhibited deficient levels, $9.5 \%$ had hypovitaminosis levels, and $26.2 \%$ had inadequate levels.

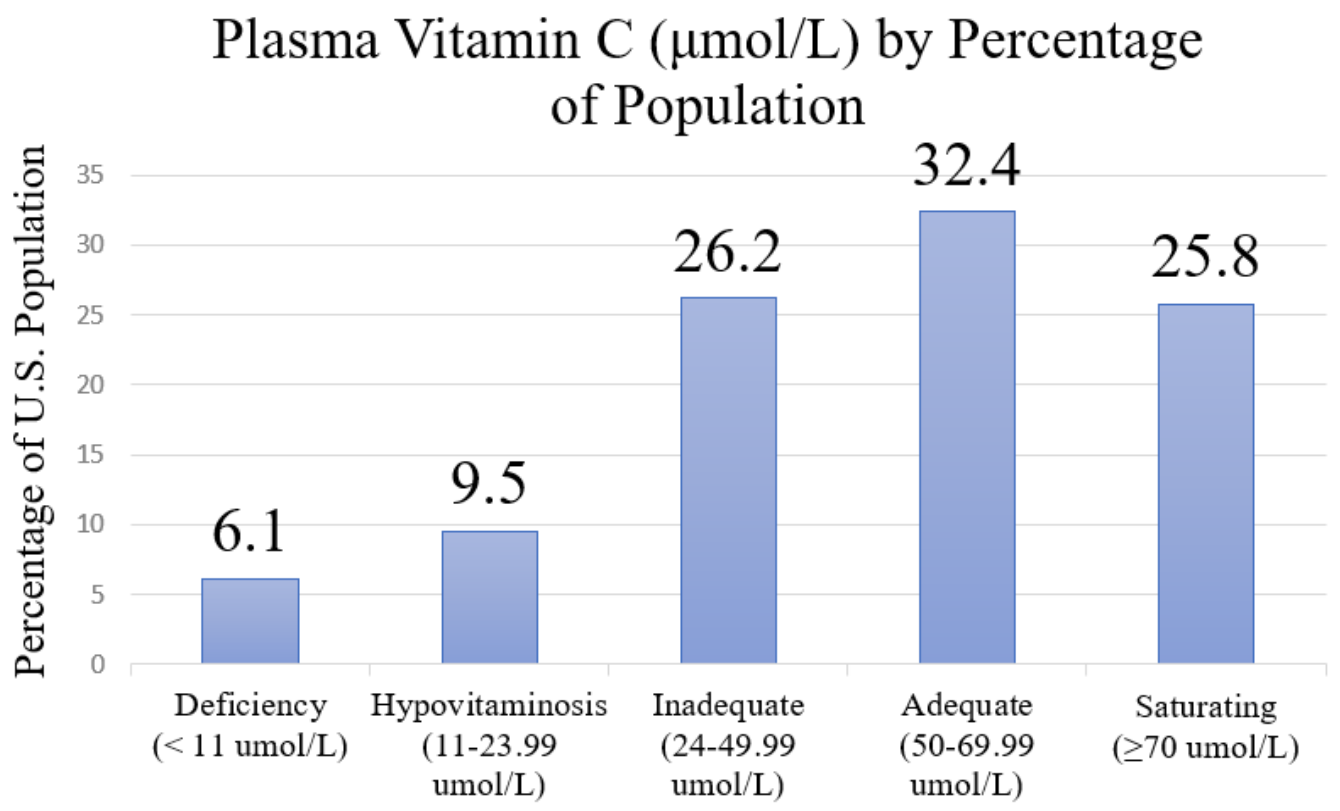

Figure 2. Prevalence of Plasma Vitamin C Levels in the USA Population in 2003-2006.

\subsection{Associations between Sample Characteristics and Vitamin C Levels}

Table 2 demonstrates the associations between sample characteristics across the five plasma Vitamin C quintiles. Significant relationships were identified for each variable.

Males $(n=3699,48.7 \%)$ were significantly more likely to exhibit insufficient levels of plasma Vitamin C (as categorized in the deficiency, hypovitaminosis, and inadequate quintiles) compared to females $(3908,51.3 \%)[\chi 2=215.82, \mathrm{df}=3.42, p<0.001]$. Assessment of saturating levels of Vitamin C revealed a wide disparity between males $(19.3 \%)$ and females (32.3\%).

There were statistically significant age differences in Vitamin $C$ categories $[\chi 2=250.45$, $\mathrm{df}=5.74, p<0.001]$. Participants in the young $(n=2751,36.5 \%)$ and middle adulthood $(n=2295,40.1 \%)$ groups were more likely to have inadequate plasma Vitamin C levels. Those in the late adulthood category $(n=2561,22.3 \%)$ had the highest percentage of saturating plasma Vitamin C levels.

Ethnicity exhibited significant differences among plasma Vitamin $C$ categories $[\mathrm{x} 2=148.28, \mathrm{df}=8.6, p=<0.001]$. Non-Hispanic Blacks $(n=1536,10.5 \%)$ demonstrated the highest levels of insufficient plasma Vitamin C (combined deficiency, hypovitaminosis, and inadequate quintiles) with $48.5 \%$, followed by 'Other' ( $n=290,4.9 \%)$ with $44.7 \%$, and Mexican Americans ( $n=1516,7.6 \%$ ) with $43.8 \%$. Participants of the category 'Other Hispanics' ( $n=230,3.4 \%$ ) revealed the lowest percentage of insufficient Vitamin C levels (combined deficiency, hypovitaminosis, and adequate quintiles) with $40.8 \%$, followed by Non-Hispanic Whites (41.4\%). White participants displayed the highest levels of both deficiency $(7.6 \%)$ and saturating $(28.2 \%)$ plasma Vitamin C. 
Table 2. Sample Characteristics by Plasma Vitamin C Quintiles.

\begin{tabular}{|c|c|c|c|c|c|c|c|c|}
\hline Characteristics & $n$ (Weighted \%) & $\begin{array}{l}\text { Deficiency } \\
n=467 \\
6.14 \%\end{array}$ & $\begin{array}{c}\text { Hypo-Vitaminosis } \\
n=722 \\
9.49 \%\end{array}$ & $\begin{array}{c}\text { Inadequate } \\
n=1991,26.17 \%\end{array}$ & $\begin{array}{c}\text { Adequate } \\
n=2467,32.43 \%\end{array}$ & $\begin{array}{c}\text { Saturating } \\
n=1960,25.77 \%\end{array}$ & $p$-Value & Effect Size ${ }^{5}$ \\
\hline $\begin{array}{l}\text { Gender } \\
\text { Male } \\
\text { Female }\end{array}$ & $\begin{array}{l}3699(48.7 \% \pm 0.5) \\
3908(51.3 \% \pm 0.5)\end{array}$ & $\begin{array}{l}8.6 \%( \pm 0.8) \\
4.9 \%( \pm 0.6)\end{array}$ & $\begin{array}{c}12.4 \%( \pm 0.8) \\
8.2 \%( \pm 0.7)\end{array}$ & $\begin{array}{l}28.2 \%( \pm 1.2) \\
23.0 \%( \pm 1.0)\end{array}$ & $\begin{array}{l}31.6 \%( \pm 1.1) \\
31.7 \%( \pm 1.3)\end{array}$ & $\begin{array}{l}19.3 \%( \pm 0.8) \\
32.3 \%( \pm 1.3)\end{array}$ & $<0.001$ & 0.17 \\
\hline $\begin{array}{c}\text { Adulthood Stage } \\
\text { Young }(20-39) \\
\text { Middle }(40-59) \\
\text { Late }(\geq 60)\end{array}$ & $\begin{array}{l}2751(36.5 \% \pm 0.8) \\
2295(40.1 \% \pm 0.8) \\
2561(22.3 \% \pm 0.5)\end{array}$ & $\begin{array}{l}6.6 \%( \pm 0.8) \\
7.9 \%( \pm 1.0) \\
4.6 \%( \pm 0.6)\end{array}$ & $\begin{array}{l}11.0 \%( \pm 0.9) \\
11.0 \%( \pm 0.7) \\
7.6 \%( \pm 0.8)\end{array}$ & $\begin{array}{l}28.9 \%( \pm 1.1) \\
26.3 \%( \pm 1.0) \\
18.5 \%( \pm 0.8)\end{array}$ & $\begin{array}{l}31.8 \%( \pm 1.3) \\
32.8 \%( \pm 1.2) \\
29.4 \%( \pm 1.5)\end{array}$ & $\begin{array}{l}21.7 \%( \pm 1.4) \\
22.1 \%( \pm 1.2) \\
40.0 \%( \pm 1.1)\end{array}$ & $<0.001$ & 0.11 \\
\hline $\begin{array}{c}\text { Race/Ethnicity } \\
\text { Mexican American } \\
\text { Other Hispanic } \\
\text { Non-Hispanic White } \\
\text { Non-Hispanic Black } \\
\text { Other }\end{array}$ & $\begin{array}{c}1516(7.6 \% \pm 1.1) \\
230(3.4 \% \pm 0.5) \\
4305(73.6 \% \pm 2.1) \\
1536(10.5 \% \pm 1.2) \\
290(4.9 \% \pm 0.4)\end{array}$ & $\begin{array}{l}3.8 \%( \pm 0.8) \\
1.3 \%( \pm 0.8) \\
7.6 \%( \pm 0.7) \\
5.5 \%( \pm 0.8) \\
3.8 \%( \pm 1.5)\end{array}$ & $\begin{array}{c}7.7 \%( \pm 1.3) \\
10.5 \%( \pm 3.1) \\
10.6 \%( \pm 0.7) \\
8.3 \%( \pm 1.0) \\
12.6 \%( \pm 2.5)\end{array}$ & $\begin{array}{l}32.3 \%( \pm 1.5) \\
29.0 \%( \pm 3.1) \\
23.2 \%( \pm 0.9) \\
34.7 \%( \pm 1.6) \\
28.3 \%( \pm 2.2)\end{array}$ & $\begin{array}{l}37.6 \%( \pm 1.8) \\
38.6 \%( \pm 4.3) \\
30.5 \%( \pm 1.1) \\
32.3 \%( \pm 1.7) \\
33.5 \%( \pm 2.6)\end{array}$ & $\begin{array}{l}18.7 \%( \pm 1.5) \\
20.6 \%( \pm 3.7) \\
28.2 \%( \pm 1.1) \\
19.1 \%( \pm 1.2) \\
21.8 \%( \pm 2.0)\end{array}$ & $<0.001$ & 0.08 \\
\hline $\begin{array}{c}\text { Family PIR }{ }^{1} \\
\text { High }(0-1.5) \\
\text { Medium }(1.51-4.5) \\
\text { Low }(>4.51)\end{array}$ & $\begin{array}{c}5206(63.8 \% \pm 1.1) \\
1614(22.7 \% \pm 0.5) \\
787(13.5 \% \pm 0.6)\end{array}$ & $\begin{array}{l}6.3 \%( \pm 0.6) \\
9.5 \%( \pm 1.6) \\
3.7 \%( \pm 1.1)\end{array}$ & $\begin{array}{l}11.1 \%( \pm 0.7) \\
9.8 \%( \pm 1.1) \\
7.0 \%( \pm 1.0)\end{array}$ & $\begin{array}{l}26.5 \%( \pm 0.7) \\
24.2 \%( \pm 1.3) \\
22.9 \%( \pm 2.4)\end{array}$ & $\begin{array}{l}31.5 \%( \pm 1.2) \\
31.0 \%( \pm 1.6) \\
33.4 \%( \pm 1.6)\end{array}$ & $\begin{array}{l}24.5 \%( \pm 0.9) \\
25.5 \%( \pm 1.8) \\
33.1 \%( \pm 2.1)\end{array}$ & 0.002 & 0.06 \\
\hline $\begin{array}{c}\text { Smoking Status } \\
\text { Yes } \\
\text { No }\end{array}$ & $\begin{array}{l}1997(29.4 \% \pm 1.0) \\
5610(70.6 \% \pm 1.0)\end{array}$ & $\begin{array}{l}14.8 \%( \pm 1.0) \\
3.3 \%( \pm 0.4)\end{array}$ & $\begin{array}{l}17.0 \%( \pm 1.2) \\
7.4 \%( \pm 0.5)\end{array}$ & $\begin{array}{l}29.0 \%( \pm 1.3) \\
24.1 \%( \pm 0.8)\end{array}$ & $\begin{array}{l}24.6 \%( \pm 1.5) \\
34.6 \%( \pm 0.8)\end{array}$ & $\begin{array}{l}14.7 \%( \pm 1.0) \\
30.7 \%( \pm 0.9)\end{array}$ & 0.001 & 0.28 \\
\hline $\begin{array}{c}\text { Food Insecure } \\
\text { Yes } \\
\text { No }\end{array}$ & $\begin{array}{l}1449(14.1 \% \pm 0.8) \\
6158(85.9 \% \pm 0.8)\end{array}$ & $\begin{array}{l}9.7 \%( \pm 1.2) \\
6.2 \%( \pm 0.6)\end{array}$ & $\begin{array}{l}13.9 \%( \pm 1.5) \\
9.6 \%( \pm 0.6)\end{array}$ & $\begin{array}{l}32.9 \%( \pm 1.1) \\
24.3 \%( \pm 0.8)\end{array}$ & $\begin{array}{l}27.3 \%( \pm 1.7) \\
32.3 \%( \pm 1.0)\end{array}$ & $\begin{array}{l}16.2 \%( \pm 1.2) \\
27.6 \%( \pm 0.9)\end{array}$ & $<0.001$ & 0.12 \\
\hline $\mathrm{BMI}^{2}$ & $7607(100 \%)$ & $29.0( \pm 7.3)$ & $29.8( \pm 7.4)$ & $29.8( \pm 6.8)$ & $28.6( \pm 6.1)$ & $27.1( \pm 5.5)$ & $<0.001^{4}$ & 0.02 \\
\hline $\begin{array}{c}\text { Vitamin C Intake }{ }^{3} \\
\text { Day One } \\
\text { Day Two }\end{array}$ & $\begin{array}{l}7468(98.1 \%) \\
6886(90.5 \%)\end{array}$ & $\begin{array}{l}39.4( \pm 55.0) \\
41.6( \pm 68.7)\end{array}$ & $\begin{array}{l}50.9( \pm 61.7) \\
60.2( \pm 74.2)\end{array}$ & $\begin{array}{l}73.5( \pm 94.1) \\
84.2( \pm 89.1)\end{array}$ & $\begin{array}{l}102.2( \pm 104.8) \\
104.7( \pm 106.8)\end{array}$ & $\begin{array}{l}124.9( \pm 119.5) \\
118.8( \pm 103.4)\end{array}$ & $<0.001^{4}$ & 0.06 \\
\hline
\end{tabular}

${ }^{1}$ Poverty to Income Ratio; ${ }^{2}$ Body Mass Index $\left(\mathrm{kg} / \mathrm{m}^{2}\right)$ presented as mean $/ \mathrm{SD} ;{ }^{3}$ Reported as $\mathrm{mg} /$ day; ${ }^{4}$ With Welch correction; ${ }^{5}$ Cramer's V (categorical) and $\mathrm{R}^{2}$ (continuous). 
Participants who reported high Poverty to Income Ratios (PIR) $(n=5206,63.8 \%)$ and medium PIR ( $n=1614,22.7 \%$ ) possessed equal levels of insufficient Vitamin $C$ with $43.9 \%$ and $43.5 \%$, respectively. Participants who reported low PIR $(n=787,13.5 \%)$, indicating higher levels of income, had the lowest percentage of insufficient levels of plasma Vitamin C with $33.6 \%$ [ $\chi 2=80.47, \mathrm{df}=4.93, p=0.002]$. Medium PIR displayed the highest proportion of individuals with Vitamin C deficiency (9.5\%).

Smoking status also found significance across the categories of plasma Vitamin C $[x 2=673.25, \mathrm{df}=3.34, p \leq 0.001]$. Smokers $(n=1997,29.4 \%)$ were more likely to fall within the insufficient plasma Vitamin $C$ quintiles of deficiency, hypovitaminosis, and inadequate $(60.8 \%)$ than non-smokers $(n=5610,70.6 \%)$, who revealed only $34.8 \%$. Only $14.7 \%$ of smokers reached saturating levels of Vitamin C compared to non-smokers (30.7\%).

Participants who acknowledged food insecurity $(n=1449,14.1 \%)$ had higher percentages of insufficient Vitamin C levels (deficiency, hypovitaminosis, and inadequate) compared to those who denied food insecurity $(n=6158,85.9 \%)[\chi 2=114.59, \mathrm{df}=3.29$, $p \leq 0.001$ ] with food insecure participants exposing $56.5 \%$ compared to $40.1 \%$ of those not food insecure. Additionally, a wide gap in saturating Vitamin C levels between participants with food insecurity (16.2\%) and those without food insecurity $(27.6 \%)$.

Mean BMIs indicated significant differences across the categories of plasma Vita$\min C[\mathrm{~F}=58.65, \mathrm{df}=4, p \leq 0.001]$. Participants with insufficient plasma Vitamin $\mathrm{C}$ levels (deficiency, hypovitaminosis, and inadequate categories) possessed ranges of BMI from $29.0 \mathrm{~kg} / \mathrm{m}^{2}-29.8 \mathrm{~kg} / \mathrm{m}^{2}$, while participants with sufficient Vitamin C (adequate and saturating categories) showed BMI ranges of $27.1 \mathrm{~kg} / \mathrm{m}^{2}-28.6 \mathrm{~kg} / \mathrm{m}^{2}$.

Vitamin $C$ intake also showed significant differences across the categories of plasma Vitamin $C$ for both non-consecutive days [Day One intake: $\mathrm{F}=134.43, \mathrm{df}=4, p \leq 0.001$; Day Two intake: $\mathrm{F}=88.84, \mathrm{df}=4, p<0.001]$. Mean ranges of reported dietary intake of Vitamin C were $39.4 \mathrm{mg}$ to $124.9 \mathrm{mg}$ for the two days collected.

\section{Discussion}

These findings are consistent with the literature that examined baseline plasma Vitamin C levels prior to implementation of Vitamin C intervention [42] and suggest that insufficient Vitamin $C$ levels remain a current public health issue.

Categorizing participants into five strata of plasma Vitamin C demonstrates the most impacted group by inadequate dietary intake and surveillance. Males were significantly more likely to be in insufficient levels of Vitamin C than females. This finding is consistent among studies examining gender differences across multiple countries $[5,43,44]$. Although some reasons may be dietary differences and volumetric dilution due to higher muscle mass [45], more research is needed to identify clear causality. Minorities were disproportionately affected by insufficiencies of Vitamin C, with both Non-Hispanic Black and Mexican Americans comprising the largest percentages of inadequate plasma Vitamin $C$ as well as the lowest rates of saturating Vitamin $C$ levels. This study corroborates the limited findings regarding Vitamin C plasma status among Black and White ethnicities [46,47]. More recent research has identified the Asian ethnicity to be at higher risk of decreased Vitamin C [6], though not captured in this study. While traditional dietary practices may partly explain the incidence, other attributes considered are the increased risk of stress in minority populations [48], higher incidence of food insecurity [49], and higher rates of obesity and type II diabetes [50], of which all are associated with decreased Vitamin C. PIR confirmed that low socioeconomic status (SES) is a crucial factor in decreased Vitamin C levels. Yet, participants, who were categorized as medium PIR (those who would be considered middle class and not eligible for federal food assistance programs), held similar rates of insufficient plasma Vitamin C levels as those in the lower income category and held the highest proportion of participants with Vitamin C deficiency. It provides evidence of a possibly overlooked segment of the population with nutritional insufficiencies contributing to increased inflammation. This study corroborated previous findings regarding the effect of smoking on decreased plasma Vitamin C levels due to the development of oxidants 
and in vivo oxidative stress $[4,51,52]$ from smoking. Individuals with food insecurity also displayed a significantly higher percentage of insufficient levels of Vitamin C. Although there is limited information regarding the nutritional deficiencies specific to areas considered food deserts, some studies have identified decreased reported dietary intake of Vitamin C among the food insecure [53], though residents are at increased risk of chronic inflammation [54]. BMI mean differences across plasma Vitamin C levels to a small degree substantiates evidence of an increased risk of insufficient Vitamin $C$ levels in individuals with increased BMI possibly due to increased rates of inflammation [55,56], volumetric dilution due to decreased muscle mass [45], and/or poor dietary intake [7]. Comparing participant dietary intakes and the small effect size seen when compared to plasma Vitamin $C$ identifies the disparity between reported intake and readily available Vitamin C within the body. This also underscores the importance of assessment of plasma/leukocytic Vitamin C status and not relying solely on dietary intake data.

This study has limitations. The use of secondary data limits the ability to define or propose new variables to the dataset. Categorizing the age variable in this study identified significant differences in plasma Vitamin $C$ though a further delineation into age ranges including later adulthood (young-old and old-old) should be considered. Vitamin C plasma levels were last observed in the NHANES studies in 2006. More recent data on the national plasma Vitamin C data would provide more updated information. Food security issues remain unclear under the current pervasiveness and severity related to unemployment and lockdowns brought on by the coronavirus pandemic [57]. The USDA updated definitions of food security in 2020, introduced in 2006, so variables included in this study are not the most current [58]. The findings cannot be generalized to institutionalized adults, such as residents of long-term care facilities. Finally, the ethnicity variables were not as diverse as today, so this study cannot clearly distinguish ethnic differences in Vitamin C levels.

Research efforts are suggested to identify the prevalence and risks of insufficient plasma Vitamin C levels in individuals of all ages (including infants and children) and more diverse race/ethnicities. Pregnancy status is another area where research is advised, as needs may transiently increase during the progression of the pregnancy [59-61]. It is also recommended to investigate both low SES and those considered middle class, as this study identified both to be significant predictors for decreased Vitamin C. Further examination of Vitamin C insufficiencies in older adults is suggested as findings may not be applied to residents of long-term care facilities, a sector with known nutritional inadequacies that would also benefit from increased surveillance and treatment [62-64].

Since plasma concentration of Vitamin C is tightly regulated [17] and is second to leukocytic measurement as a reliable estimate of actual body storage, it is recommended that future research study laboratory processing advancements for Vitamin C so it can be assessed in both inpatient and outpatient settings.

\section{Conclusions}

The identification of increased supplementation necessary to reverse hypovitaminosis [11] as well as the uncertainty of the pervasiveness of food insecurity caused by the coronavirus pandemic, highlight the importance of nutritional surveillance and better tailored interventions. Research has previously identified that approximately $25 \%$ of the population consumed less than the recommended daily amount (RDA) of Vitamin C [2]. This study provides evidence from plasma blood levels that suggest that percentage of Vitamin $C$ insufficiency is much higher. Disregarding nutritional insufficiencies leads not only to a lack of awareness and policy change within the community but limits potentially beneficial treatment options. The vitamin $C$ status of the population. This study provides a clear examination of the prevalence of insufficient Vitamin $C$ by separating participant plasma levels into quintiles of deficiency, hypovitaminosis, inadequate, adequate, and saturating. A large segment of the sample contained participants with inadequate levels of Vitamin C, exposing a population who may not exhibit any overt symptoms of scurvy, but are still at risk for inflammatory driven diagnoses, allowing practitioners to redefine patients who 
are considered at risk. Vitamin $C$ has a long history in research, though its benefits and mechanisms of action are still not fully understood. Surveillance is not consistent, and this study contributes to a limited amount of literature delineating the prevalence of five specific categories of plasma Vitamin C levels within the USA The increased prevalence of individuals with insufficient plasma Vitamin $C$ provides conclusive evidence that dietary intake of Vitamin C is still not where it should be.

Author Contributions: Conceptualization, J.C. and V.J.-M. methodology, J.C. and A.H.; writingoriginal draft preparation, J.C.; writing-review and editing J.C., A.H., S.-J.Y., O.G., and V.J.-M.; supervision V.J.-M. All authors have read and agreed to the published version of the manuscript.

Funding: This research received no external funding.

Institutional Review Board Statement: The study was conducted according to the guidelines of the Declaration of Helsinki and approved by the Institutional Review Board of the University of Florida (protocol\# 201902929 approved 27 August 2020).

Informed Consent Statement: Informed consent was obtained from all subjects involved in the study.

Data Availability Statement: Publicly available datasets were analyzed in this study. This data can be found on the Centers for Disease Control and Prevention (CDC) website at: https://www.cdc. gov/nchs/nhanes/index.htm.

Conflicts of Interest: The authors declare no conflict of interest.

\section{References}

1. Beaulac, J.K.; Cummins, S.E. A systematic review of food deserts, 1966-2007. Prev. Chronic Dis. 2009, 6, 105.

2. Carr, A.C.; Frei, B. Toward a new recommended dietary allowance for vitamin $C$ based on antioxidant and health effects in humans. Am. J. Clin. Nutr. 1999, 69, 1086-1107. [CrossRef]

3. Ver Ploeg, M.; Breneman, V.; Farrigan, T.; Hamrick, K.; Hopkins; Kaufman, P.; Lin, B.; Nord, M.; Smith, T.A.; Williams, R.; et al. Access to Affordable and Nutritious Food-Measuring and Under-Standing Food Deserts and Their Consequences: Report to Congress; United States Department of Agriculture: Washington, DC, USA, 2009; p. 160.

4. Carr, A.C.; Rowe, S. Factors Affecting Vitamin C Status and Prevalence of Deficiency: A Global Health Perspective. Nutrients 2020, 12, 1963. [CrossRef]

5. Rowe, S.; Carr, A.C. Global Vitamin C Status and Prevalence of Deficiency: A Cause for Concern? Nutrients 2020, 12, 2008. [CrossRef]

6. Khan, R.M.; Iqbal, M.P. Deficiency of vitamin C in South Asia. Pak. J. Med. Sci. 2006, 22, 347.

7. Canoy, D.; Wareham, N.; Welch, A.; Bingham, S.; Luben, R.; Day, N.; Khaw, K.-T. Plasma ascorbic acid concentrations and fat distribution in 19068 British men and women in the European Prospective Investigation into Cancer and Nutrition Norfolk cohort study. Am. J. Clin. Nutr. 2005, 82, 1203-1209. [CrossRef] [PubMed]

8. Carr, A.C. A new clinical trial to test high-dose vitamin C in patients with COVID-19. Crit. Care 2020, 24, 1-2. [CrossRef]

9. Hemila, H.; Chalker, E. Vitamin C as a possible therapy for COVID-19. Infect. Chemother. 2020, 52, 222-223. [CrossRef] [PubMed]

10. Carr, A.C.; Rowe, S. The Emerging Role of Vitamin C in the Prevention and Treatment of COVID-19. Nutrients 2020, 12, 3286. [CrossRef]

11. Carr, A.C.; Pullar, J.M.; Bozonet, S.M.; Vissers, M.C. Marginal ascorbate status (hypovitaminosis C) results in an attenuated response to vitamin $C$ supplementation. Nutrients 2016, 8, 341. [CrossRef]

12. Frei, B.; Birlouez-Aragon, I.; Lykkesfeldt, J. Authors' perspective: What is the optimum intake of vitamin C in humans? Crit. Rev. Food Sci. Nutr. 2012, 52, 815-829. [CrossRef]

13. Bengmark, S. Gut microbiota, immune development and function. Pharmacol. Res. 2013, 69, 87-113. [CrossRef] [PubMed]

14. Elste, V.; Troesch, B.; Eggersdorfer, M.; Weber, P. Emerging evidence on neutrophil motility supporting its usefulness to define vitamin C intake requirements. Nutrients 2017, 9, 503. [CrossRef]

15. Gorkom, G.W.; Van Elssen, C.R.; Wieten, L.; Germeraad, W.; Bos, G. Influence of vitamin C on lymphocytes: An overview. Antioxidants 2018, 7, 41. [CrossRef]

16. Huijskens, M.; Walczak, M.; Sarkar, S.; Atrafi, F.; Senden-Gijsbers, B.; Tilanus, M.; Bos, G.M.J.; Wieten, L.; Germeraad, W.T.V. Ascorbic acid promotes proliferation of natural killer cell populations in culture systems applicable for natural killer cell therapy. Crytotherapy 2015, 17, 613-620. [CrossRef]

17. Levine, M.; Padayatty, S.J.; Espey, M.G. Vitamin C: A concentration-function approach yields pharmacology and therapeutic discoveries. Adv. Nutr. 2011, 2, 78-88. [CrossRef]

18. Pehlivan, F.E. Vitamin C: An antioxidant agent. Vitam. C 2017, 2, 23-35.

19. Bakalova, R.; Zhelev, Z.; Miller, T.; Aoki, I.; Higashi, T. Vitamin C versus Cancer: Ascorbic Acid Radical and Impairment of Mitochondrial Respiration? Oxid. Med. Cell. Longev. 2020, 2020, 1504048. [CrossRef] 
20. Cimmino, L.; Neel, B.G.; Aifantis, I. Vitamin C in Stem Cell Reprogramming and Cancer. Trends Cell Biol. 2018, $28,698-708$. [CrossRef]

21. Bruno, R.S.; Traber, M.G. Vitamin E biokinetics, oxidative stress and cigarette smoking. Pathophysiology 2006, 13, 143-149. [CrossRef]

22. Packer, J.E.; Slater, T.F.; Willson, R.L. Direct observation of a free radical interaction between vitamin E and vitamin C. Nature 1979, 278, 737-738. [CrossRef]

23. Heffernan, A.; Evans, C.; Holmes, M.; Moore, J.B. The regulation of dietary iron bioavailability by vitamin C: A systematic review and meta-analysis. Proc. Nutr. Soc. 2017, 76, OCE4. [CrossRef]

24. Young, J.I.; Züchner, S.; Wang, G. Regulation of the epigenome by vitamin C. Annu. Rev. Nutr. 2015, 35, 545-564. [CrossRef]

25. CCamarena, V.; Wang, G. The epigenetic role of vitamin C in health and disease. Cell. Mol. Life Sci. 2016, 73, 1645-1658. [CrossRef] [PubMed]

26. Klose, R.J.; Kallin, E.M.; Zhang, Y. JmjC-domain-containing proteins and histone demethylation. Nat. Rev. Genet. 2006, 7, 715-727. [CrossRef] [PubMed]

27. Choi, S.-W.; Friso, S. Epigenetics: A New Bridge between Nutrition and Health. Adv. Nutr. 2010, 1, 8-16. [CrossRef]

28. Schleicher, R.L.; Carroll, M.D.; Ford, E.S.; Lacher, D.A. Serum vitamin C and the prevalence of vitamin C deficiency in the United States: 2003-2004 National Health and Nutrition Examination Survey (NHANES). Am. J. Clin. Nutr. 2009, 90, 1252-1263. [CrossRef]

29. Carr, A.C.; Lykkesfeldt, J. Discrepancies in global vitamin C recommendations: A review of RDA criteria and underlying health perspectives. Crit. Rev. Food Sci. Nutr. 2021, 61, 742-755. [CrossRef] [PubMed]

30. National Health and Nutrition Examination Survey Data 2005-2006; US Department of Health and Human Services, Centers for Disease Control and Prevention: Hyattsville, MD, USA, 2008.

31. Plotnick, M.D.; D'Urzo, K.A.; Gurd, B.J.; Pyke, K.E. The influence of vitamin C on the interaction between acute mental stress and endothelial function. Graefe's Arch. Clin. Exp. Ophthalmol. 2017, 117, 1657-1668. [CrossRef]

32. Moritz, B.; Schmitz, A.E.; Rodrigues, A.L.S.; Dafre, A.; Cunha, M.P. The role of vitamin C in stress-related disorders. J. Nutr. Biochem. 2020, 85, 108459. [CrossRef] [PubMed]

33. Bailey, R.L.; Akabas, S.R.; Paxson, E.E.; Thuppal, S.V.; Saklani, S.; Tucker, K. Total Usual Intake of Shortfall Nutrients Varies with Poverty Among US Adults. J. Nutr. Educ. Behav. 2017, 49, 639-646.e3. [CrossRef]

34. Ellulu, M.S. Obesity, cardiovascular disease, and role of vitamin $C$ on inflammation: A review of facts and underlying mechanisms. Inflammopharmacology 2017, 25, 313-328. [CrossRef]

35. Thomas-Valdés, S.; Tostes, M.D.G.V.; Anunciação, P.C.; Silva, B.; Sant'Ana, H.M.P. Association between vitamin deficiency and metabolic disorders related to obesity. Crit. Rev. Food Sci. Nutr. 2017, 57, 3332-3343. [CrossRef]

36. Schectman, G.; Byrd, J.C.; Gruchow, H.W. The influence of smoking on vitamin C status in adults. Am. J. Public Health 1989, 79, 158-162. [CrossRef] [PubMed]

37. Pelletier, O. Smoking and Vitamin C Levels in Humans. Am. J. Clin. Nutr. 1968, 21, 1259-1267. [CrossRef] [PubMed]

38. Karademirci, M.; Kutlu, R.; Kilinc, I. Relationship between smoking and total antioxidant status, total oxidant status, oxidative stress index, vit C, vit E. Clin. Respir. J. 2018, 12, 2006-2012. [CrossRef]

39. Carr, A.C.; Maggini, S. Vitamin C and Immune Function. Nutrients 2017, 9, 1211. [CrossRef] [PubMed]

40. Healthy People 2030; United States Department of Agriculture: Washington, DC, USA, 2021.

41. Schmidt, A.F.; Finan, C. Linear regression and the normality assumption. J. Clin. Epidemiol. 2018, 98, 146-151. [CrossRef]

42. Wilson, R.W.J.; Gearry, R.B.; Hughes, A.; Lawley, B.; Skidmore, P.; Frampton, C.; Fleming, E.; Anderson, A.; Jones, L.; Tannock, G.W.; et al. SunGold kiwifruit supplementation of individuals with prediabetes alters gut microbiota and improves Vitamin C status, anthropometric and clinical markers. Nutrients 2018, 10, 895. [CrossRef]

43. Alishahi, A.; Azizbeigi, K.; Salamat, K.M.; Yektayar, M. The Effect of Aerobic Training with Vitamin C Supplementation on Myeloperoxidase, Asymmetric Dimethyl Arginine and Blood Pressure in Middle-Age Hypertensive Overweight Men. J. Clin. Res. Paramedical Sci. 2019, 8, e86843. [CrossRef]

44. Paalanen, L.; Prättälä, R.; Alfthan, G.; Salminen, I.; Laatikainen, T. Vegetable and fruit consumption, education and plasma vitamin C concentration in Russian and Finnish Karelia, 1992-2002. Public Health Nutr. 2013, 17, 2278-2286. [CrossRef] [PubMed]

45. Jungert, A.; Neuhäuser-Berthold, M. The lower vitamin C plasma concentrations in elderly men compared with elderly women can partly be attributed to a volumetric dilution effect due to differences in fat-free mass. Br. J. Nutr. 2015, 113, 859-864. [CrossRef]

46. Ness, A.R.; Cappuccio, F.P.; Atkinson, R.W.; Khaw, K.T.; Cook, D.G. Plasma vitamin C levels in men and women from different ethnic backgrounds living in England. Int. J. Epidemiol. 1999, 28, 450-455. [CrossRef]

47. Koh, E.T.; Chi, M.S.; Lowenstein, F.W. Comparison of selected blood components by race, sex, and age. Am. J. Clin. Nutr. 1980, 33, 1828-1835. [CrossRef] [PubMed]

48. Brown, L.L.; Mitchell, U.A.; Ailshire, J.A. Disentangling the Stress Process: Race/Ethnic Differences in the Exposure and Appraisal of Chronic Stressors Among Older Adults. J. Gerontol. Ser. B 2020, 75, 650-660. [CrossRef]

49. Vaccaro, J.A.; Huffman, F.G. Sex and race/ethnic disparities in food security and chronic diseases in US older adults. Gerontol. Geriatr. Med. 2017, 3, 2333721417718344. [CrossRef] [PubMed] 
50. Thornton, P.L.; Kumanyika, S.K.; Gregg, E.W.; Araneta, M.R.; Baskin, M.L.; Chin, M.H.; Crespo, C.J.; de Groot, M.; Garcia, D.O.; Haire-Joshu, D.; et al. New research directions on disparities in obesity and type 2 diabetes. Ann. N. Y. Acad. Sci. 2020, 1461, 5-24. [CrossRef]

51. Lykkesfeldt, J.; Viscovich, M.; Poulsen, H.E. Plasma malondialdehyde is induced by smoking: A study with balanced antioxidant profiles. Br. J. Nutr. 2004, 92, 203-206. [CrossRef] [PubMed]

52. McCall, S.J.; Clark, A.B.; Luben, R.N.; Wareham, N.J.; Khaw, K.T.; Myint, P.K. Plasma Vitamin C levels: Risk factors for deficiency and association with self-reported functional health in the European Prospective Investigation into Cancer-Norfolk. Nutrients 2019, 11, 1552. [CrossRef] [PubMed]

53. Cowan, A.E.; Jun, S.; Tooze, J.A.; Eicher-Miller, H.A.; Dodd, K.W.; Gahche, J.J.; Guenther, P.M.; Dwyer, J.T.; Potischman, N.; Bhadra, A.; et al. Total usual micronutrient intakes compared to the dietary reference intakes among US adults by food security status. Nutrients 2020, 12, 38. [CrossRef] [PubMed]

54. Kelli, H.M.; Hammadah, M.; Ahmed, H.; Ko, Y.-A.; Topel, M.; Samman-Tahhan, A.; Awad, M.; Patel, K.; Mohammed, K.; Sperling, L.S.; et al. Association Between Living in Food Deserts and Cardiovascular Risk. Circ. Cardiovasc. Qual. Outcomes 2017, 10, 003532. [CrossRef] [PubMed]

55. Karczewski, J.; Śledzińska, E.; Baturo, A.; Jończyk, I.; Maleszko, A.; Samborski, P.; Dobrowolska, A. Obesity and inflammation. Eur. Cytokine Netw. 2018, 29, 83-94. [CrossRef]

56. Kwaifa, I.K.; Bahari, H.; Yong, Y.K.; Noor, S.M. Endothelial Dysfunction in Obesity-Induced Inflammation: Molecular Mechanisms and Clinical Implications. Biomolecules 2020, 10, 291. [CrossRef] [PubMed]

57. Laborde, D.; Martin, W.; Swinnen, J.; Vos, R. COVID-19 risks to global food security. Science 2020, 369, 500-502. [CrossRef] [PubMed]

58. Definitions of Food Insecurity: Ranges of Food Security and Insecurity; United States Department of Agriculture: Washington, DC, USA, 2020.

59. Darma, I.Y.; Arni, A.; Basyir, V. The Relationship Vitamin C Level and MMP-2 Serum with Premature Rupture of Membranes and Normal Pregnancy. World J. Res. Rev. 2018, 7, 9-12. [CrossRef]

60. Juhl, B.; Lauszus, F.F.; Lykkesfeldt, J. Poor Vitamin C Status Late in Pregnancy Is Associated with Increased Risk of Complications in Type 1 Diabetic Women: A Cross-Sectional Study. Nutrients 2017, 9, 186. [CrossRef]

61. Gupta, S.; Gaikwad, H.S.; Nath, B.; Batra, A. Can vitamin C and interleukin 6 levels predict preterm premature rupture of membranes: Evaluating possibilities in North Indian population. Obstet. Gynecol. Sci. 2020, 63, 432-439. [CrossRef] [PubMed]

62. Abbasi, A.A.; Rudman, D. Observations on the Prevalence of Protein-Calorie Undernutrition in VA Nursing Homes. J. Am. Geriatr. Soc. 1993, 41, 117-121. [CrossRef]

63. Assis, B.S.; Jairza, J.M.B.-M.; Lopes, J.A.; Roriz, A.K.C.; Melo, A.L.; Previdell, A.; Aquino, R.D.C.; Ramos, L.B. Micronutrient intake in elderly living in nursing homes. Nutr. Hosp. 2018, 35, 59-64. [CrossRef] [PubMed]

64. Keller, H.H.; Lengyel, C.; Carrier, N.; Slaughter, S.E.; Morrison, J.; Duncan, A.M.; Steele, C.M.; Duizer, L.; Brown, K.S.; Chaudhury, H.; et al. Prevalence of inadequate micronutrient intakes of Canadian long-term care residents. Br. J. Nutr. 2018, 119, 1047-1056. [CrossRef] 